\title{
Effect of Strong Electrolytes on Edible Oils Part 1: Viscosity of Sunflower Oil In 1,4- Dioxane at Different Temperatures
}

\section{${ }^{1}$ A.RASHEED KHAN (R); ${ }^{2}$ SHAMA, REHANA SAEED; ${ }^{2}$ FAHIM UDDIN*}

\author{
${ }^{1}$ Pakistani Council for Scientific and Industrial Research PCSIR Laboratories Karachi \\ ${ }^{2}$ Department of Chemistry, University of Karachi Pakistan \\ E-mail: fahim_uddin01@yahoo.com
}

\begin{abstract}
The viscosity of sunflower oil in 1,4-dioxane used as a diluent in the presence and absence of strong electrolytes ( $\mathrm{HCl}, \mathrm{NaOH}, \mathrm{NaCl}$ ) at different temperatures (298K to $323 \mathrm{~K}$ ) was accomplished. The viscosity of sunflower oil was found to increase with the increasing concentration and decreased with the increase in temperature. It was further observed that viscosity of sunflower solution in 1,4-dioxane increases under the influence of electrolytes. The values of Jones-Dole coefficient A and B were evaluated. The positive values of Bcoefficient increased with the rise of temperature. This led to conclusion that ion-solvent interactions increase and electrolytes such as $\mathrm{HCl}, \mathrm{NaOH}$ and $\mathrm{NaCl}$ behave as structure breaker in sunflower-1,4-dioxane system. The change in the values of fluidity parameters such as $\left(\mathrm{a}, \mathrm{k}, \alpha_{1}, \alpha_{2}, \beta, \beta^{*}\right)$ with concentration of oil and temperature suggests that fluidity parameters are structural. The energy of activation $\left(\Delta \mathrm{E}_{\mathrm{v}}\right)$, latent heat of vapourization $\left(\Delta \mathrm{L}_{\mathrm{v}}\right)$ and molar volume of oil $\left(\mathrm{V}_{\mathrm{m}}\right)$ were also calculated. Effect of electrolytes show that, the concentration of electrolytes increases the value of $\left(\Delta \mathrm{E}_{\mathrm{v}}\right)$ and $\left(\Delta \mathrm{L}_{\mathrm{v}}\right)$ whereas the value of molar volume $\left(\mathrm{V}_{\mathrm{m}}\right)$ decrease with the concentration of oil and electrolytes. In brief, unsaturations of fatty acids of oil are responsible for the changes in the values of different parameters determined. The results for $\left(\Delta \mathrm{E}_{\mathrm{v}}\right)$ and $\left(\Delta \mathrm{L}_{\mathrm{v}}\right)$ are influenced by the concentration of sunflower oil. @JASEM
\end{abstract}

The importance of oils and fats in human nutrition is well recognized (Salunkhe et al 1992). These form of vital components of many cell constituents are an important source of energy and act as a carrier of fatsoluble vitamins. Besides they contribute significantly as function of ingredients in improving the sensory characteristics of several process food products. The ingredients of oils are the glyceric compounds of glycols and fatty acids. They are usually triglycerides in which one molecule of glycerols has combined with three molecules of fatty acids with the elimination of three molecules of water. The three molecules of fatty acids are rarely of but one kind so that the glycerides are mainly mixed triglycerides. Monoglycerides may be present in fatty acids to varying percentage, diglycerides are more rarely present. Free fatty acids and unsaponificable matter e.g., sterols, fatty alcohols hydrocarbons coloring matter etc are also the part of fatty acids. The edible oils, which are in daily human use, include canola, soyabean, peanut, cottonseed, sunflower, mustard, palm oils etc. These edible oils are major energy source of the human and animal organism. The energy values of fatty acids depend on their chain length. It decreased with the reduction of carbon (C) atoms. $\mathrm{C}_{6}-\mathrm{C}_{8}$ fatty acids contain only 34 $\mathrm{kJg}^{-1}$ whilst $38 \mathrm{kJg}^{-1}$ is obtained from the fatty acids containing $\mathrm{C}_{16}-\mathrm{C}_{18}$ atoms (Shama 2004). The main aim to revise the importance of edible oils for the use of human diet is to find out the effect of electrolytes like $\mathrm{HCl}, \mathrm{NaOH}$ and $\mathrm{NaCl}$, which are some how the others are related to digestion of human food. What happens when these electrolytes come in contact with edible oils? The effect of these electrolytes is studied on the viscosities of oil solution as a function of electrolytes concentration and temperature. The viscosities are measured in 1, 4-dioxane. The oil selected, for this study is extracted from the seeds of sunflower.

\section{EXPERIMENTAL}

Material: 1,4-dioxane (BDH), $\mathrm{HCl}, \mathrm{NaOH}, \mathrm{NaCl}$, oxalic acid of E. Merk were used without further purification. Oil of sunflower was extracted from dried and dehulled seeds. Sunflower seeds were bought from the local market in Karachi, Pakistan. Oil was extracted from washed, dried, dehulled and crushed sunflower seeds. Extracted oil was filtered and used without further purification. The density of oil at $298 \mathrm{~K}$ was determined as $0.978 \mathrm{~g} . \mathrm{cm}^{-3}$.

Procedure: Experiments are accomplished to measure the viscosities and densities of oil solutions in 1,4-dioxane in the presence of electrolytes. Viscosities of oil solutions in 1,4-dioxane are measured at different temperatures ranging from 298K to 323K with the help of Ostwald viscometer. Temperature was kept constant through out the course of experiment with the help of a thermostatic water bath type (circulator model YCM-01, volt 230Ac, Hz 50, Amp 5). A known fixed volume of oil

\footnotetext{
*Corresponding author: E-mail: fahim_uddin01@yahoo.com
} 
solution was taken in viscometer, temperature of the solution was maintained by placing the viscometer in the thermostatic water bath having a constant circulation of water. Densities of solvent and solutions were measured with the help of relative density bottle having a capacity of $10 \mathrm{ml}$ by volume at different temperatures. Viscosities and densities were measured as a function of oil concentration, electrolytes concentrations and temperatures. Each measurement was recorded at least three times to ensure the reproducibility in the observations.

solutions (5-25\%) is measured in 1,4-dioxane at different temperatures ranging from $298 \mathrm{~K}$ to $323 \mathrm{~K}$ with the help of Ostwald type viscometer. The results are summarized in Table 2 and shown graphically in Fig. 1. These results reveal that viscosity of oil increases with increase in concentration of oil and gets decreased as the mercury level rises in Fig. 2. volume of oil up to temperature $323 \mathrm{~K}$ spreads slowly and changes in unsaturation occur. Viscosity of oil

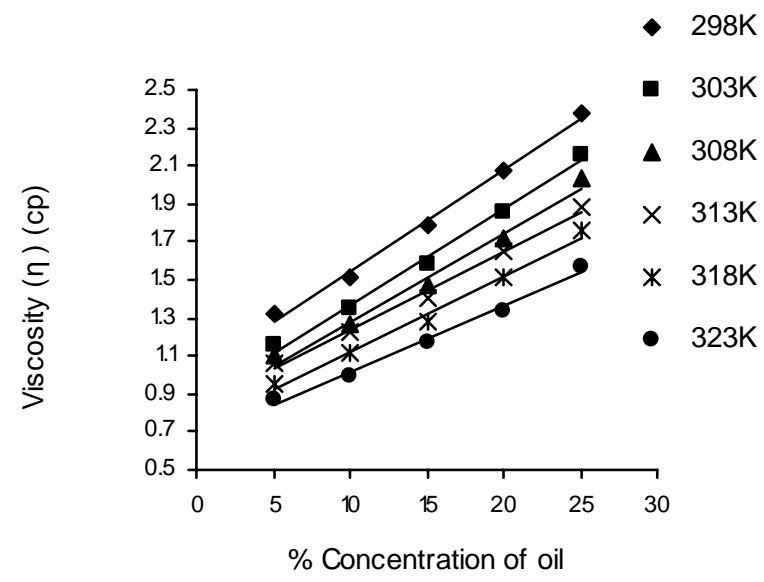

Fig. 1 : Plot of viscosity ( $\eta$ ) (cp) of sunflow er oil versus $\%$ concentration.

Table 1. Densities of sunflower oil at different temperatures (K)

\begin{tabular}{|c|c|c|c|c|c|c|}
\hline Temperature (K) & 298 & 303 & 308 & 313 & 318 & 323 \\
\hline Density (g. $\mathrm{cm}^{-3}$ ) & 0.978 & 0.975 & 0.972 & 0.967 & 0.962 & 0.955 \\
\hline
\end{tabular}

Table 2: Viscosities of sunflower oil in 1,4 -dioxane at different temperatures (K).

\begin{tabular}{ccccccc}
\hline $\begin{array}{c}\text { Concentration } \\
\text { of oil (\%) }\end{array}$ & \multicolumn{5}{c}{ Viscosity (cp) at different temperature (K) } \\
\cline { 2 - 7 } & $\underline{298}$ & $\underline{303}$ & $\underline{308}$ & $\underline{313}$ & $\underline{318}$ & $\underline{323}$ \\
5.0 & 1.317 & 1.160 & 1.101 & 1.061 & 0.957 & 0.873 \\
10 & 1.519 & 1.356 & 1.261 & 1.227 & 1.122 & 0.999 \\
15 & 1.784 & 1.578 & 1.479 & 1.407 & 1.285 & 1.177 \\
20 & 2.073 & 1.856 & 1.725 & 1.646 & 1.513 & 1.341 \\
25 & 2.377 & 2.164 & 2.032 & 1.883 & 1.755 & 1.562 \\
\hline
\end{tabular}

Table 3 includes the results obtained due to the effect of addition of $\mathrm{HCl}$ on the viscosity of oil solution in 1,4-dioxane. These results indicate that as the concentration of $\mathrm{HCl}$ increases, the viscosity of oil gets increased. But on comparison of these results with the viscosity obtained in the absence of electrolytes shows that the addition of $\mathrm{HCl}$ reduces the viscosity. Furthermore viscosities remained decrease with the rise in temperature. Similarly Table 4 illustrates the results obtained for the addition of $\mathrm{NaOH}$ in different concentration. These results show that the addition of $\mathrm{NaOH}$ in oil solution reduces the viscosity at all temperatures and electrolytes concentration. 
Table 3: Effect of $\mathrm{HCl}$ on viscosities (cp) of 5\% sunflower oil solution in 1,4-dioxane at different temperatures $(\mathrm{K})$

\begin{tabular}{ccccccc}
\hline $\begin{array}{c}{[\mathrm{HCl}] 10^{3}} \\
\left(\mathrm{~mol} . \mathrm{dm}^{-3}\right)\end{array}$ & \multicolumn{7}{c}{ Viscosity (cp) at different temperatures (K) } \\
\cline { 2 - 7 } & $\underline{298}$ & $\underline{303}$ & $\underline{308}$ & $\underline{313}$ & $\underline{318}$ & $\underline{323}$ \\
1.0 & 1.297 & 1.142 & 1.100 & 1.051 & 0.950 & 0.820 \\
2.0 & 1.415 & 1.279 & 1.156 & 1.061 & 0.974 & 0.925 \\
3.0 & 1.432 & 1.296 & 1.173 & 1.084 & 0.990 & 0.921 \\
4.0 & 1.450 & 1.314 & 1.189 & 1.100 & 1.006 & 0.936 \\
5.0 & 1.502 & 1.363 & 1.222 & 1.148 & 1.022 & 0.981 \\
\hline
\end{tabular}

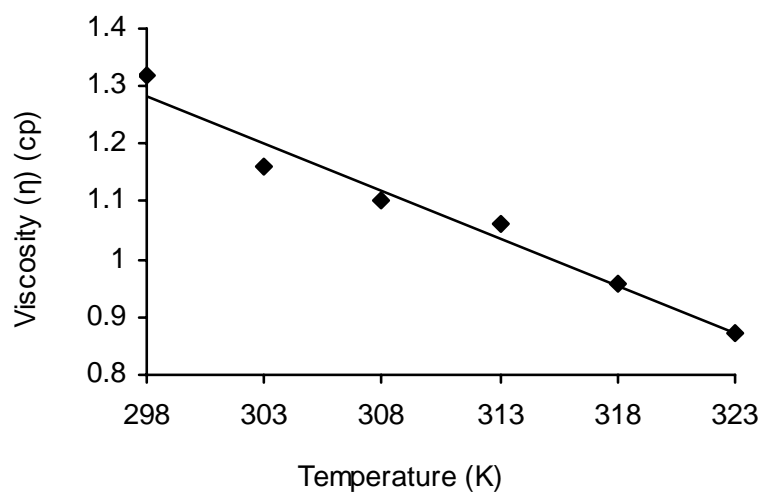

Fig. 2: Plot of Viscosity (n) (cp) against

temperature $(\mathrm{K})$.

The addition of $\mathrm{NaCl}$ Table 5 in the oil of solution (5\%) decreases the viscosity at all concentration of $\mathrm{NaCl}$ and temperature ranges $298 \mathrm{~K}$ to $323 \mathrm{~K}$. Hydrochloric acid $(\mathrm{HCl})$ is more efficient in reducing the viscosity values of oil than obtained for $\mathrm{NaOH}$ and $\mathrm{NaCl}$. According to the analysis [Williams 1966] based on hundreds of experiments, oil of sunflower consist mostly glycerides of oleic acid (25-42\%), linoleic acid (52-66\%) and saturated acid (5-13\%). The change of viscosity at variable temperature in the presence and absence of electrolytes may be probably due to the unsaturation of ingredients present in the oil. Thermal effect activates radically the oleic and linoleic acids and as results of, the electrolytes attach to the glycerides of these fatty acids, which increases the movement of oil solution. Besides, the results are also analyzed by the variation in $\mathrm{pH}$ values. The value of $\mathrm{pH}$ of 1,4-dioxane is obtained as 5.15 and for the oil concentration of $5 \%(\mathrm{v} / \mathrm{v})$ oil solutions in 1,4-dioxane, the $\mathrm{pH}$ reduced to 2.8 . The change in $\mathrm{pH}$ reveals that the hydrogen ion concentration was increased by dissolving the oils in 1,4-dioxane
[Shama 2004, Williams 1966, Adesun and Ipinmoroti 1999]. The same results were also obtained by titrating the oil solutions versus standard sodium hydroxide. As more volume of sodium hydroxide consumed to titrate the oil solution as compared to 1,4-dioxane, the electrolytes reduce the viscosities and when a strong electrolyte of acidic nature as hydrochloric acid $(\mathrm{HCl})$ is added to the solutions it further decreases the viscosities. It may be due to the increase in uncoiling and increase in concentration of monomers and decrease in intermolecular interaction. Furthermore when $\mathrm{NaOH}$ is added to the oil solution, it is observed that with the increase in $\mathrm{pH}$ the viscosities are reduced as compared to the acidic medium as in alkaline medium oil molecules form the sodium salt of stearic acid. As a result the long chain association was decreasing, due to the decrease in intermolecular interactions (Falkenhagen and Dole 1929, Jones and Dole 1929, Blokhra and Kumar 1983, Das and Das 1983, Robson 1988, Saeed et al 2002). 
Table 4: Effect of $\mathrm{NaOH}$ on viscosities (cp) of 5\% sunflower oil solution in 1,4-dioxane at different temperatures $(\mathrm{K})$

\begin{tabular}{ccccccc}
\hline $\begin{array}{c}{[\mathrm{NaOH}] 10^{3}} \\
\left.(\mathrm{mol.dm})^{-3}\right)\end{array}$ & \multicolumn{6}{c}{ Viscosity (cp) at different temperatures (K) } \\
\cline { 2 - 7 } & $\underline{298}$ & $\underline{303}$ & $\underline{308}$ & $\underline{313}$ & $\underline{318}$ & $\underline{323}$ \\
1.0 & 1.300 & 1.148 & 1.181 & 1.067 & 0.998 & 0.932 \\
2.0 & 1.423 & 1.276 & 1.193 & 1.082 & 1.013 & 0.947 \\
3.0 & 1.437 & 1.299 & 1.214 & 1.099 & 1.029 & 0.963 \\
4.0 & 1.455 & 1.316 & 1.231 & 1.116 & 1.045 & 0.978 \\
5.0 & 1.474 & 1.380 & 1.248 & 1.148 & 1.061 & 0.994 \\
\hline
\end{tabular}

Table 5: Effect of $\mathrm{NaCl}$ on viscosities (cp) of 5\% sunflower oil solution in 1,4-dioxane at different temperatures $(\mathrm{K})$.

\begin{tabular}{ccccccc}
\hline $\begin{array}{c}{[\mathrm{NaCl}] 10^{3}} \\
\left(\mathrm{~mol} . \mathrm{dm}^{-3}\right)\end{array}$ & \multicolumn{6}{c}{ Viscosity (cp) at different temperatures (K) } \\
\cline { 2 - 7 } & $\underline{298}$ & $\underline{303}$ & $\underline{308}$ & $\underline{313}$ & $\underline{318}$ & $\underline{323}$ \\
1.0 & 1.300 & 1.210 & 1.155 & 1.116 & 0.992 & 0.921 \\
2.0 & 1.420 & 1.225 & 1.170 & 1.131 & 1.008 & 0.937 \\
3.0 & 1.417 & 1.242 & 1.187 & 1.148 & 1.023 & 0.953 \\
4.0 & 1.433 & 1.258 & 1.204 & 1.164 & 1.038 & 0.967 \\
5.0 & 1.500 & 1.290 & 1.236 & 1.181 & 1.054 & 1.012 \\
\hline
\end{tabular}

When a solute is dissolved in a solvent, two types of interactions take place ion-ion and ion-solvent interactions. According to Falkenhagen Theory (Falkenhagen and Dole 1929) in unperturbed solutions of electrolytic interactions to the viscosity of medium, each ion is associated with a spherically symmetric ionic cloud of oppositely charged shearing forces. These charged shearing forces generated under an applied linear velocity gradient cause the ionic cloud to deform from a spherical to an ellipsoidal from and Falkenhagen's theory is neglected due to the incomplete dissociation and ion association. One can regard Jones-Dole equation (Jones and Dole 1929).

$$
\eta_{s p}=\frac{A+B \sqrt{C}}{\sqrt{C}}
$$

where $\eta_{\mathrm{sp}}$ is the specific viscosity, $\mathrm{C}$ is molar concentration and ' $\mathrm{A}$ ' and ' $\mathrm{B}$ ' are, respectively the intercept and slope of linear plots $\eta_{\mathrm{sp}} / \sqrt{ } \mathrm{C}$ versus $\sqrt{C}$. They are Jones-Dole coefficients representing ion-ion and ion-solvent interaction characterizing the behavior of electrolytes.

Table 6: Ion- ion and Ion- solvent interactions of sunflower oil with 1,4-dioxane in presence of electrolytes at different temperatures $(\mathrm{K})$.

\begin{tabular}{|c|c|c|c|}
\hline \multirow[t]{2}{*}{$\begin{array}{l}\text { Temperature } \\
\text { (K) }\end{array}$} & \multicolumn{3}{|c|}{$\begin{array}{l}\text { Ion-Ion and Ion-Solvent Interactions as } \\
\text { A and B Coefficient of Jones-Dole equation }\end{array}$} \\
\hline & $\mathrm{HCl}$ & $\mathrm{NaOH}$ & $\mathrm{NaCl}$ \\
\hline & \multicolumn{3}{|c|}{ A-Coefficient $\left(\mathrm{dm}^{3} \mathrm{~mol}^{-1}\right)^{1 / 2}$} \\
\hline 298 & -2.485 & -1.789 & -1.775 \\
\hline 303 & -2.420 & -2.027 & -1.790 \\
\hline 308 & -2.630 & -2.487 & -1.927 \\
\hline 313 & -3.720 & -2.713 & -1.932 \\
\hline 318 & -3.392 & -3.216 & -2.540 \\
\hline 323 & -3.752 & -3.151 & -3.627 \\
\hline \multicolumn{4}{|c|}{ B-Coefficient ( $\left.\mathrm{dm}^{3} \mathrm{~mol}\right)$} \\
\hline 298 & 41.207 & 34.485 & 32.048 \\
\hline 303 & 41.417 & 39.640 & 32.890 \\
\hline 308 & 42.354 & 40.999 & 35.383 \\
\hline 313 & 52.948 & 43.161 & 36.983 \\
\hline 318 & 53.420 & 47.565 & 40.694 \\
\hline 323 & 59.029 & 49.676 & 56.914 \\
\hline
\end{tabular}


Table 7: Fluidity parameters a, $\mathrm{k}, \alpha_{1}, \beta, \alpha_{2}$, and $\beta^{*}$ of $5 \%(\mathrm{v} / \mathrm{v})$ sunflower oil solution in 1,4-dioxane at various temperatures.

\begin{tabular}{ccccccc}
\hline Temperature & \multicolumn{7}{c}{ Fluidity Parameters } \\
\cline { 2 - 7 }$(\mathrm{K})$ & $\mathrm{a}$ & $\mathrm{K}$ & $\alpha_{1}$ & $\beta$ & $\alpha_{2}$ & $\beta^{*}$ \\
& & & & & & \\
298 & 0.364 & 0.698 & 0.394 & -0.137 & 0.448 & -0.167 \\
303 & 0.379 & 0.599 & 0.334 & -0.126 & 0.383 & -0.157 \\
308 & 0.367 & 0.580 & 0.314 & -0.126 & 0.363 & -0.160 \\
313 & 0.350 & 0.575 & 0.326 & -0.144 & 0.371 & -0.177 \\
318 & 0.341 & 0.537 & 0.286 & -0.135 & 0.328 & -0.168 \\
323 & 0.351 & 0.473 & 0.264 & -0.141 & 0.302 & -0.174 \\
\hline
\end{tabular}

Table 8: Energy of activation $\left(\Delta \mathrm{E}_{\mathrm{v}}\right)$ Latent heat of vapourization $\left(\Delta \mathrm{L}_{\mathrm{v}}\right)$ and Molar volume $\left(\mathrm{V}_{\mathrm{m}}\right)$ of sunflower oil in 1,4-dioxane.

\begin{tabular}{cccc}
\hline $\begin{array}{c}\text { Oil concentration } \\
\%(\mathrm{v} / \mathrm{v})\end{array}$ & $\begin{array}{c}\Delta \mathrm{E}_{\mathrm{v}} \\
\left(\mathrm{KJ}_{\mathrm{mol}}{ }^{-1}\right)\end{array}$ & $\begin{array}{c}\Delta \mathrm{L}_{\mathrm{v}} \\
\left(\mathrm{KJ}_{\mathrm{mol}}{ }^{-1}\right)\end{array}$ & $\begin{array}{c}\mathrm{V}_{\mathrm{m}}\left(10 \mathrm{e}^{8}\right) \\
(\mathrm{dl})\end{array}$ \\
\hline 5 & 11.85 & 29.62 & 3.65 \\
10 & 12.24 & 30.62 & 3.67 \\
15 & 12.49 & 31.23 & 3.48 \\
20 & 12.74 & 31.86 & 3.45 \\
25 & 12.86 & 32.15 & 2.84 \\
\hline
\end{tabular}

The values of $\mathrm{A}$ and B-coefficient of Jones-Dole equation (Saeed et al 2002) are determined graphically from the intercept and slope of linear plots of $\eta_{\mathrm{sp}} / \sqrt{C}$ versus $\sqrt{C}$ respectively Fig. 3 . The values of $A$ and $B$ obtained graphically are shown in Table 6. The negative values of A-coefficient are obtained. We find variation in the values of Acoefficient, which show incomplete dissociation and ion association of electrolytes with sunflower oil in 1,4-dioxane system (Blokhra and Kumar 1983). For oil solution in 1,4-dioxane the negative values of Acoefficient generally decrease with the rise in mercury level. Some irregular variation in Acoefficient is observed for oil in the presence of sodium chloride $(\mathrm{NaCl})$. The decrement in the values of A-coefficient with rise in temperature is due to the fact that A-coefficient depends on the stiffering effect of the space lattice. The effect is greater at low temperature because the space lattice is less distributed by heat variation. The increasing order of negative values may also be due to the greater thermal agitation at higher temperature and also due to the decrement of attractive forces (Das and Das 1983). This shows that Jones-Dole equation competes over Falkenhagen theory (Robson 1988), as in presence of electrolytes the solutions of oil in 1,4dioxane have low values of A-coefficient (Jones and Dole,1929).

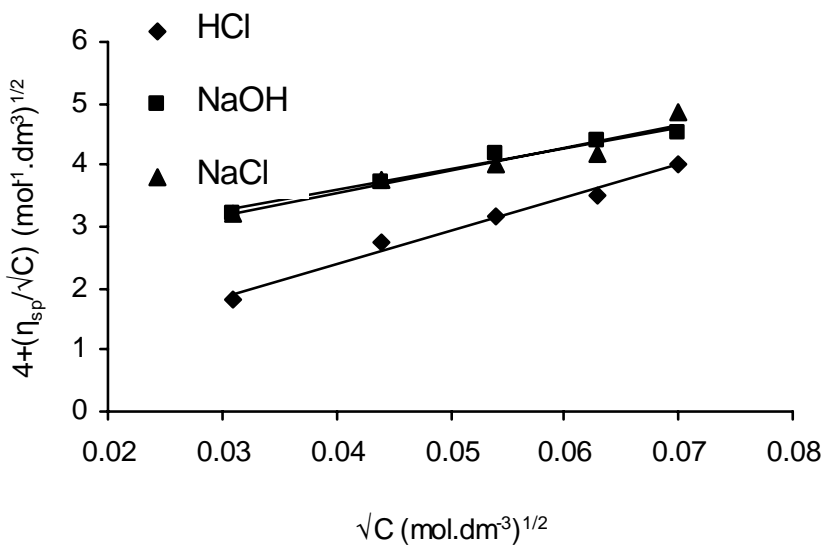

Fig. 3 : Plot of $\eta_{\text {sp }} / \sqrt{ } C$ versus $\sqrt{ } C$ for sunflower oil in electrolytes at $298 \mathrm{~K}$ 
The B-coefficient of Jones-Dole equation represents the ion-solvent interaction. Temperature and composition of solvent may affect the values of Bcoefficient. Results show that the values of solutesolvent interaction in terms of B-coefficient are positive and increase with the rise in temperature for oil solution in 1,4-dioxane system in the presence of electrolytes. The increment in positive values with the rise of temperature reveals that electrolytes behave as structure breaker in 1,4-dioxane. It should be noted that when B-coefficient increases with the temperature, this indicates that viscosity decreases due to the solvent structure. Distortion of solvent structure is small which results the positive values of B-coefficient. It should also be noted that positive values of B-coefficient if decreases with the rise in mercury level show structure making in nature. Similar results are obtained for the sodium citrate solutions in acidic aqueous methanol (Uddin et al 1989), lithium chloride and sodium chloride in aqueous-butanol system [Khan et al 2003], Sodium chloride in aqueous-methanol system [Khan et al 2002]. All these system show that both ion-ion interaction and ion-solvent vary with this composition of solvents. The positive values of Bcoefficient decreased with rise in temperature led to the conclusion that these electrolytes $(\mathrm{NaCl}, \mathrm{LiCl})$ in aqueous butanol mixtures behave as structure maker where as in aqueous medium $\mathrm{NaCl}$ and $\mathrm{LiCl}$ showing negative values of B-coefficient behave as a structure breaker.

Table 9: Effect of electrolytes on Energy of activation $\left(\Delta \mathrm{E}_{\mathrm{v}}\right)$, Latent heat of vapourization $\left(\Delta \mathrm{L}_{\mathrm{v}}\right)$ and Molar volume $\left(\mathrm{V}_{\mathrm{m}}\right)$ of sunflower oil $(5 \% \mathrm{v} / \mathrm{v})$ in 1,4-dioxane.

\begin{tabular}{|c|c|c|c|}
\hline Electrolyte & Energy of Activation & Latent heat of vapourization & Molar volume of oil \\
\hline $\begin{array}{c}{[\mathrm{HCl}] 10^{3}} \\
\left(\mathrm{~mol} . \mathrm{dm}^{-3}\right)\end{array}$ & $\begin{array}{c}\Delta \mathrm{E}_{\mathrm{v}} \\
\left(\mathrm{KJ}^{-\mathrm{mol}^{-1}}\right)\end{array}$ & $\begin{array}{c}\Delta \mathrm{L}_{\mathrm{v}} \\
\left(\mathrm{KJ}_{\mathrm{mol}}{ }^{-1}\right)\end{array}$ & $\begin{array}{c}\mathrm{V}_{\mathrm{m}}\left(10 \mathrm{e}^{8}\right) \\
\text { (dl) }\end{array}$ \\
\hline 1.0 & 10.34 & 25.87 & 9.17 \\
\hline 2.0 & 13.84 & 34.61 & 8.52 \\
\hline 3.0 & 13.88 & 34.72 & 1.87 \\
\hline 4.0 & 14.17 & 35.42 & 7.47 \\
\hline 5.0 & 17.30 & 35.77 & 7.08 \\
\hline \multicolumn{4}{|l|}{$[\mathrm{NaOH}] 10^{3}$} \\
\hline 1.0 & 12.38 & 30.69 & 4.35 \\
\hline 2.0 & 12.42 & 31.07 & 4.21 \\
\hline 3.0 & 12.58 & 31.45 & 4.60 \\
\hline 4.0 & 12.58 & 31.45 & 4.40 \\
\hline 5.0 & 12.66 & 31.66 & 4.31 \\
\hline \multicolumn{4}{|l|}{$[\mathrm{NaCl}] 10^{3}$} \\
\hline 1.0 & 11.60 & 29.02 & 3.66 \\
\hline 2.0 & 11.42 & 29.31 & 3.49 \\
\hline 3.0 & 11.84 & 29.60 & 3.23 \\
\hline 4.0 & 11.89 & 29.73 & 3.05 \\
\hline 5.0 & 11.96 & 29.90 & 3.24 \\
\hline
\end{tabular}

Fluidity is important parameters, which concern with the structure in the viscous flow. Different relations of viscosities and volume are used to evaluate the fluidity parameters i.e, a, $k, \alpha_{1}, \beta \alpha_{2}$, and $\beta^{*}$. These parameters are evaluated from the following relations (Adesun and Ipinmoroti 1999):

$\log \eta=\log k+a \log V_{o}$

$\eta / \mathrm{V}_{\mathrm{o}}=\alpha_{1}+\beta \eta$

$1 / \mathrm{V}_{\mathrm{o}}=\alpha_{2} / \eta+\beta^{*}$

a, $\mathrm{k}, \alpha_{1}, \beta, \alpha_{2}$ and $\beta^{*}$ are empirical constant and they are structural parameters.

The intercept and slope of $\log \eta$ versus $\log \mathrm{V}_{\mathrm{o}}$ gives the values of ' $k$ ' and ' $a$ '. Similarly the value of fluidity parameters $\alpha_{1}, \beta$ and $\alpha_{2}, \beta^{*}$ are evaluated from the slopes and intercepts of respective plots of $\eta / V_{0}$ versus viscosity and $1 / \mathrm{V}_{0}$ versus $1 / \eta$. All the results are summarized in Table 7 . The results show that the values of ' $k$ ' and ' $a$ ' gradually decrease with the rise of temperature suggesting that ' $a$ ' and ' $k$ ' are structural parameter. The values of parameter ' $\alpha_{1}$ ' decrease with increment of temperature revealing it dependent to be on viscosity whereas ' $\beta$ ' values negatively increase with the rise of temperature. Both ' $\alpha_{1}$ ' and ' $\beta$ ' are empirical constant. The values of $\alpha_{2}$ decrease with rise of temperature and $\beta^{*}$ values show negatively increase suggesting that $\alpha_{2}$ might be structural parameter.

The values of energy of activation $\left(\Delta \mathrm{E}_{\mathrm{v}}\right)$, Latent heat of vapourization $\left(\Delta \mathrm{L}_{\mathrm{v}}\right)$ and molar volume of oils $\left(\mathrm{V}_{\mathrm{m}}\right)$ 
are calculated. The values of energy of activation $\left(\Delta E_{v}\right)$ and molar volume of oils $\left(V_{m}\right)$ are calculated from the slope and intercept of the linear plot of logn versus $1 / \mathrm{T}$ respectively. The value of slope is used in determining the energy of activation $\left(\Delta \mathrm{E}_{\mathrm{v}}\right)$ by the following expression [Berry et al 1980, Atkins 1990]:

$\Delta \mathrm{E}_{\mathrm{v}}=$ Slope $\times \mathrm{R} \times 2.303$

Whereas the Latent heat of vapourization $\left(\mathrm{L}_{\mathrm{v}}\right)$ is evaluated from the relation:

$$
\Delta \mathrm{E}_{\mathrm{v}}=0.4 \mathrm{~L}_{\mathrm{v}}
$$

Similarly the molar volume of oil $\left(\mathrm{V}_{\mathrm{m}}\right)$ is determined from the following expression:

$$
\log \mathrm{V}_{\mathrm{m}}=\left[\log \mathrm{h} \mathrm{N}_{\mathrm{A}}-\mathrm{C}\right]
$$

here $\mathrm{h}, \mathrm{N}_{\mathrm{A}}$ and $\mathrm{C}$ represents Planck's constant, Avogadros number and intercept of plot of logn versus $1 / \mathrm{T}$ respectively. The results for the energy of activation $\left(\Delta \mathrm{E}_{\mathrm{v}}\right)$, latent heat of vapourization $\left(\Delta \mathrm{L}_{\mathrm{v}}\right)$ and molar volume of oil $\left(\mathrm{V}_{\mathrm{m}}\right)$ are illustrated in Table 8. The results show that the energy of activation $\left(\Delta \mathrm{E}_{\mathrm{v}}\right)$ and latent heat of vapourization $\left(\Delta \mathrm{L}_{\mathrm{v}}\right)$ are influenced by concentration of oil. These parameters increase with the increment in concentration, the numbers of molecules of oil are greater and cause hindrance in the mobility of molecules. Furthermore the molar volume of oils $\left(\mathrm{V}_{\mathrm{m}}\right)$ decreases with increase in concentration of oil. Effect of electrolytes Table 9 on these parameters show that the concentration of electrolytes increases the value of $\left(\Delta \mathrm{E}_{\mathrm{v}}\right)$ and $\left(\Delta \mathrm{L}_{\mathrm{v}}\right)$ whereas the value of $\left(\mathrm{V}_{\mathrm{m}}\right)$ decrease with the concentration of electrolyte.

\section{REFERENCES}

Adesun, B. F. Ipinmoroti, K.O. (1999) Preliminary measurements of fluidity and activation parameters of flow of some Nigerian vegetable oils in kerosene diluent, Pak. J. Sci. Ind. Res., 42, 6, 325-331.

Atkins. P. N. (1990) "Physical. Chemistry”, Oxford University Press, Oxford., p 671.

Berry, R. S. Rice, S. A. Russ, T. (1980) "Physical Chemistry” John Wiley and sons.,Inc. New York pp 1093-1094.

Blokhra, R. L. Kumar, S. (1983) Solute-solvent interactions in multicomponent electrolyte solutions, J. Ind. Chem. Soc., 60, 27-29.
Das, P. K. Das, P. B. (1983) Viscosity of $\mathrm{Sr}\left(\mathrm{NO}_{3}\right)_{2}$ and $\mathrm{Cd}\left(\mathrm{NO}_{3}\right)_{2}$ in mixed solvents at different temperatures. J. Ind. Chem. Soc., 60, 501-502.

Falkenhagen, H. Dole, M. (1929) Square-root law of viscosity of strong electrolytes. Z. Physik. Chem. B, 6, 159-62.

Jones, G. Dole, M. (1929) The viscosity of aqueous solutions of strong electrolytes with special reference to barium chloride. J. Am. Chem. Soc., 51,10, 2950-2968.

Khan, A. R. Uddin, F. Saeed, R. (2003) Effect of lithium chloride and sodium chloride on ionic interaction of dilute solution in aqueous butanol. Pak. J. Sci. Ind. Res., 46, 3, 151-155.

Khan, A. R. Uddin F. Saeed, R. Qureshi, W. (2002) Effect of electrolyte on ionic interactions of dilute solution of poly (vinyl alcohol) at different temperatures. Pak. J. Sci. Ind. Res., 45, 6, 378382.

Robson, R. W. (1988) "The nature of electrolyte solutions.” Macmillan Education Ltd.,p p 83-84.

Saeed, R. Uddin, F. Fazal., A. (2002) Effect of electrolyte concentration on viscous flow of polymer solutions. J. Chem. Eng. Data., 47,1359-1362.

Salunkhe, D. K. Chavan, J. K. Adsule, R. N. Kadam, S. S. (1992) "World Oil Seeds Technology and Utilization”, pp 1-2.

Shama. (2004) M.Phil Thesis entitled "Effect of strong electrolytes on the ionic interactions and activation parameters for the flow of oils in 1,4dioxane at different temperatures." University of Karachi.

Uddin, F. Adhami, I. M. Zahid, M. (1989) Viscosity of sodium citrate solutions in acidic aqueous methanol. Kimya Ve Sanayi., 32, 108 -115.

Williams, K. A. (1966) “Oils, Fats and Fatty foods.” $\mathrm{J}$ and A Churchil Ltd. Gloucester, London W-1. 